\begin{tabular}{|c|c|c|}
\hline$+1+4$ & $\begin{array}{l}\text { European Association for the } \\
\text { Development of Renewable Energies, Environment } \\
\text { and Power Quality (EA4EPQ) }\end{array}$ & $\begin{array}{l}\text { International Conference on Renewable Energies and Power Quality } \\
\text { (ICREPQ'12) } \\
\text { Santiago de Compostela (Spain), 28th to 30th March, } 2012\end{array}$ \\
\hline
\end{tabular}

\title{
An optimization power method for Photovoltaic array by tracking Maximum Average Current through Diode of Boost Converter
}

\author{
X.L. Dang ${ }^{1}$, E. Hoang ${ }^{1}$, M. Petit ${ }^{2}$, H.T. Pham ${ }^{3}$ and H. Ben Ahmed ${ }^{4}$ \\ ${ }^{1}$ SATIE, ENS de Cachan, CNRS, UniverSud, 61, av President Wilson F-94230-Cachan, France. \\ ${ }^{2}$ Department of Energy, Supélec, Campus de Gif-sur_Yvette, 91192 GIF SUR YVETTE, France. \\ ${ }^{3}$ Department of Power System, Hanoi University of Technology, Hanoi, Vietnam. \\ ${ }^{4}$ SATIE-Brittany Branch, ENS de Cachan-Ker Lann Campus, 35170 BRUZ, France. \\ E-mail: $\underline{x d a n g @ s a t i e . e n s-c a c h a n . f r ~}$
}

\begin{abstract}
In this paper, a method to optimize the power delivered by the Photovoltaic array (PV array) is presented by tracking the Maximum Average Current (MAC) passing through the diode of DC/DC boost converter. The main difference between the proposed method and the other Maximum Power Point Tracking (MPPT) methods is that instead of tracking maximum power point directly on PV array, this method enables to search the maximum power of $\mathrm{PV}$ array by tracking the maximum power output of the DC/DC converter with only one current sensor. An hybrid power system, which includes a PV array, a DC/DC boost converter, an ideal battery and a resistor, is built and simulated in MATLAB/Simulink. The comparison between analytical and simulated results has proven that this method could be applied under various irradiation and photovoltaic temperature conditions.
\end{abstract}

\section{Key words}

Hybrid Power System, Photovoltaic array (PV array), Maximum Average Current (MAC), DC/DC Boost Converter, Maximum Power Point Tracking (MPPT).

\section{Introduction}

In recent years, the development on the installed capacity and the improvement on the efficiency of the renewable energy sources are implemented in many countries around the world due to the exhaustion and pollution of fossil fuels. One of the most attractive renewable energy sources is photovoltaic array, because PV is the most direct way to convert solar radiation into electricity and is based on the photovoltaic effect [2]. Otherwise, there is no mechanical moving parts, no noise, no pollution and PV panels have a long lifetime. Moreover, the energy source is the sun which is free, ubiquitous and inexhaustible. In some popular appliances, it is usually used in charging battery, hybrid vehicles, water pumping and connecting into Distributed Energy Resources (DER) systems.

As a power source generated by solar array depending so much on the solar radiation, temperature and array voltage, it is essential to control the operating points to yield the maximum power from the PV array. In the last few decades, some methods have been proposed in [4]-[8] for tracking the maximum output power from the PV array in the last few decades. Once the PV array is connected to other elements in the hybrid system such as the battery and the load, it is required to investigate a method that could optimize the electric power delivered by the PV array. The voltage over the battery is assumed constant during the calculation period.

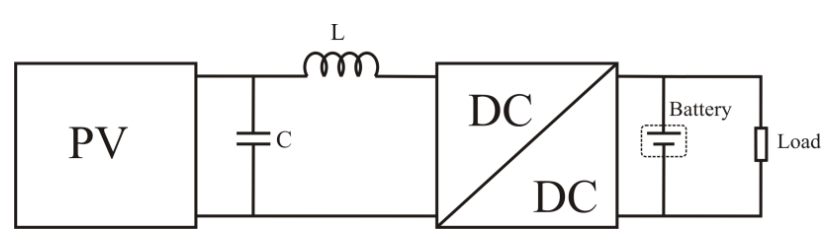

Fig. 1. Overview circuit of the PV array system

Due to the ability of keeping the voltage over the battery (and also the output voltage of DC/DC Boost Converter) constant during the simulation time, it is necessary to track the maximum current passes through the diode of DC/DC Boost Converter in order to optimize the electric power from PV array that supplies to the battery and the load. However, this current is not a continuous one which depends on the duty cycle of the switch of the Boost Converter. Hence the average current value through the diode is considered as a parameter to optimize the power from PV array. This is the main idea of the proposed method which is focused on tracking the MAC through diode.

\section{Photovoltaic array model}

The general current - voltage (I-V) characteristic of a solar cell is given by the following equation [2]:

$I_{P V}=I_{P H}-I_{S}\left[\exp \left(\frac{q\left(V_{P V}+I_{P V} R_{S}\right)}{k T_{C} A}\right)-1\right]-\frac{\left(V_{P V}+I_{P V} R_{S}\right)}{R_{S H}}$ 
Where $I_{P H}$ is the light-generated current or photocurrent, $I_{S}$ is the cell saturation of dark current, $q$ is the electron charge $\left(q=1.6 \times 10^{-19} \mathrm{C}\right), k$ is the Boltzmann's constant $\left(k=1.38 \times 10^{-23} \mathrm{~J} / \mathrm{K}\right), T_{C}$ is the cell's working temperature, $A$ is an ideal factor, $R_{S H}$ is the shunt resistance and $R_{S}$ is the series resistance.

For an array model, the series resistance has a large impact on the slope of the I-V curve near the open-circuit voltage and the shunt down resistances approaches infinity which is assumed to be open [3]. The mathematical equation model [2] to express the relation between current and voltage of the photovoltaic array is represented by the following equation:

$$
I_{P V}=N_{P} I_{P H}-N_{P} I_{S}\left[\exp \left(\frac{q\left(V_{P V} / N_{S}+I_{P V} R_{S} / N_{P}\right)}{k T_{C} A}\right)-1\right]
$$

Where $N_{S}$ is series number of cells of PV array and $N_{p}$ is series-parallel number of PV array.

It is well known that the output current and power characteristics of PV array are non-linear and vitally affected by the solar radiation and the panel temperature. Each curve in the $\mathrm{P}-\mathrm{V}$ characteristics has a maximum power point, which is the optimal operating point for the efficient use of the PV array.

\section{The proposed MAC method}

Most MPPT techniques attempt to track the PV voltage that results in the maximum power point $\mathrm{V}_{\mathrm{MPP}}$, or to find the PV current $\mathrm{I}_{\mathrm{MPP}}$ corresponding to the maximum power point. The proposed method searches for the maximum average current value passing through the diode in the DC/DC Boost Converter by changing the value of duty cycle $\left(D=t_{O N} / T\right)$ of switch IGBT from 0 to 1 . Where T is the switching period (equal to the inverse of the switching frequency $f_{S}$ ), generally lies in the range of 1 $\mathrm{kHz}$ to $1 \mathrm{MHz}$ [1], which depends on the switching speed of the semiconductor devices.

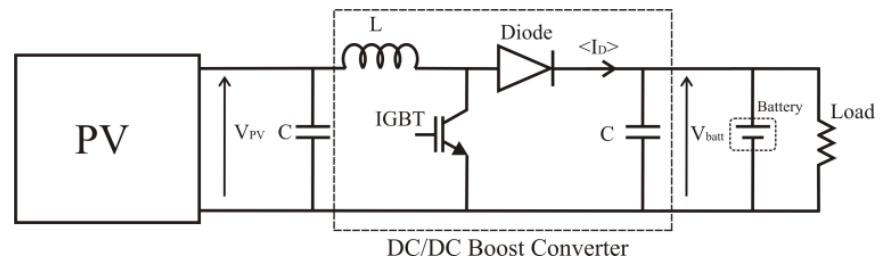

Fig. 2. Detailed circuit of the proposed PV array system

From the Fig.2 above, when the switch IGBT is "off", the diode is connected to the inductor. Using the small-ripple approximation, the inductor current is equal to the output current of PV array, so the current through the diode $\mathrm{i}_{\mathrm{D}}(\mathrm{t})$ is obtained:

$$
i_{D}(t)=i_{P V}(t)
$$

Once the IGBT is "on", the inductor connects parallel with the previous capacitor and the diode is blocked the current in the opposite direction known as the reverse direction, lead to:

$$
i_{D}(t)=0
$$

When the converter operates in steady-state, neglecting losses in these elements of the converter and assuming that the converter is perfectly efficient, the average current value or dc component through the diode is given by the equation below:

$$
\left\langle i_{D}\right\rangle=I_{P V}(1-D)
$$

From the equations (2) and (5), this average current is defined in steady-state as:

$\left\langle I_{D}\right\rangle=\left\{N_{P} I_{P H}-N_{P} I_{S}\left[\exp \left(\frac{q\left(V_{P V} / N_{S}+I_{P V} R_{S} / N_{P}\right)}{k T_{C} A}\right)-1\right]\right\}(1-D)$

Otherwise, the relation between voltage output and voltage input of the DC/DC boost converter is expressed by the following equation:

$$
V_{I N}=V_{\text {OUT }}(1-D)
$$

From the Fig.2, in steady-state, $\mathrm{V}_{\mathrm{OUT}}=\mathrm{V}_{\text {Batt }}$ and $\mathrm{V}_{\mathrm{IN}}=$ $\mathrm{V}_{\mathrm{PV}}$, and replacing these voltages into equation (7) yields:

$$
V_{P V}=V_{\text {Batt }}(1-D)
$$

Introducing the equation (8) into equation (6), the current could be expressed as following:

$\left\langle I_{D}\right\rangle=\left\{N_{P} I_{P H}-N_{P} I_{S}\left[\exp \left(\frac{q\left(V_{B a t r}(1-D) / N_{S}+I_{P V} R_{S} / N_{P}\right)}{k T_{C} A}\right)-1\right]\right\}(1-D)$

Thus the equation (9) gives the expression of the mean diode current as function of the duty cycle. For the sake of doing that, a proposed MAC model is designed by using MATLAB/Simulink and taking into account conducting losses in the IGBT, diode and inductor. From Fig. 4(a) and Fig. 4(b), it is noticed that there is always one value of the duty cycle for which the maximum of the average current through diode is achieved.

In addition, a Tracking and Holding Maximum Value (THMV) model is built to detect the maximum current and the duty cycle value at this maximum point as shown in Fig. (3).
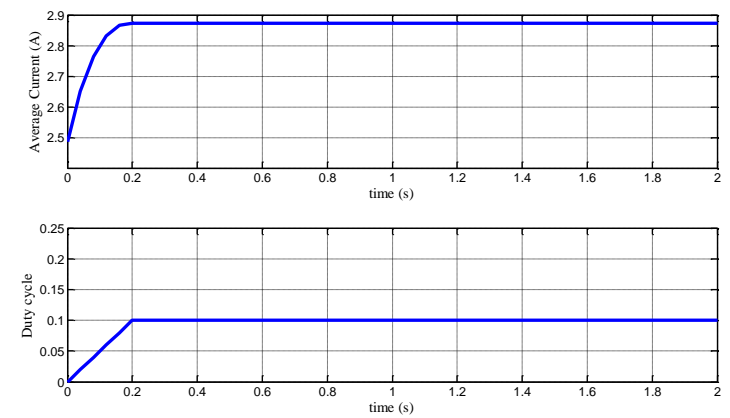

Fig.3. Tracking and Holding Maximum Value 


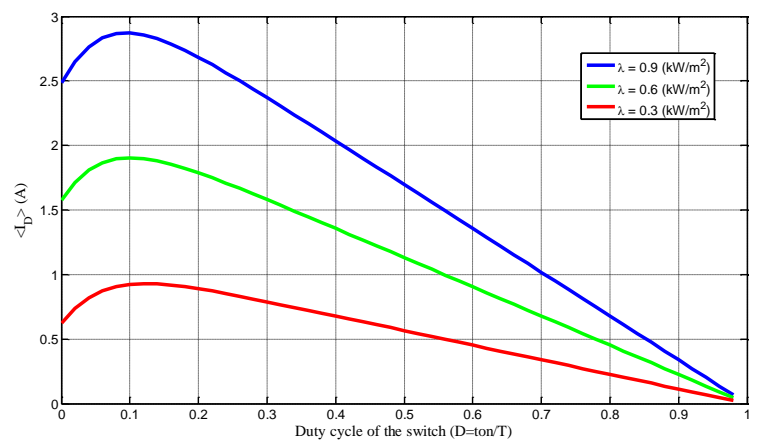

Fig. 4(a). Average current waveform through the diode with different solar radiations $(\lambda)$

\section{Simulation model and results}

The detailed power circuit of the proposed solar array system is shown in Fig. 7. The system consists of a nonlinear power source (PV array), a transferring power unit (DC/DC boost converter), a storage energy unit (battery) and a consumption energy element (a resistor). This system has been simulated in MATLAB/Simulink to verify the proposed MAC method.

The load are a resistor and a battery which is charged by the boost chopper. The Pulse Width Modulator (PWM) Generator block was used to control the IGBT with a switching frequency $\mathrm{f}_{\mathrm{s}}=1 \mathrm{kHz}$. A Repeating Sequence block was added with the triangular waveform to create the value of duty cycle of switch change from 0 to 1 and the amplitude of the waveform inside the block is set from -1 to 1 during a given period. Furthermore, this block acts as a reference modulating signal that is compared to the triangular carrier waveform inside the PWM generator.

The current from the diode is sent to a Mean Value block in order to measure the average current through the diode. And then, this average current is led to the THMV block to find and then kept the maximum value during the given period.

Under three different atmospheric conditions with solar radiations $\left(\lambda=300 \mathrm{~W} / \mathrm{m}^{2} ; 600 \mathrm{~W} / \mathrm{m}^{2}\right.$ and $\left.900 \mathrm{~W} / \mathrm{m}^{2}\right)$ and ambiance temperatures $\left(\mathrm{T}_{\mathrm{C}}=15^{\circ} \mathrm{C} ; 35^{\circ} \mathrm{C}\right.$ and $\left.55^{\circ} \mathrm{C}\right)$. the reference modulating signal for controlling the switch IGBT and the average current through the diode are shown as the simulation results in Fig. 5(a) and Fig. 5(b).
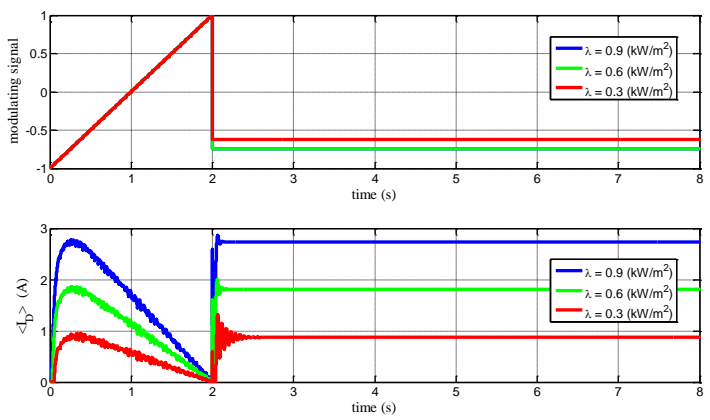

Fig. 5(a). Tracking and Holding the MAC value through the diode with different solar radiations

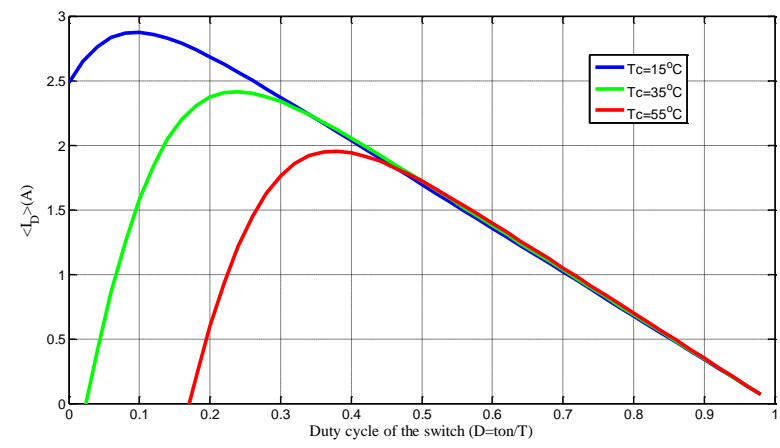

Fig. 4(b). Average current waveform through the diode with different temperatures $(\mathrm{Tc})$
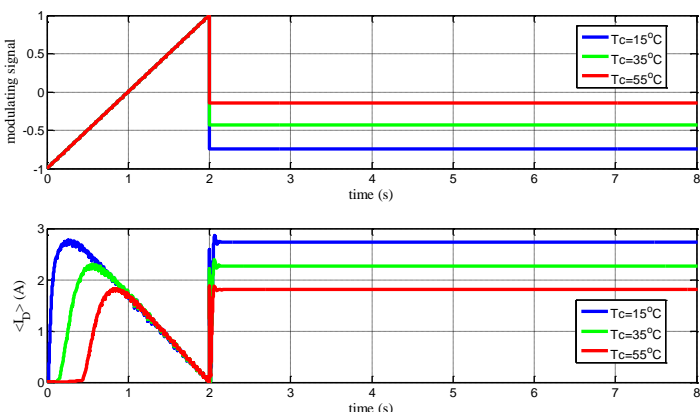

Fig. 5(b). Tracking and Holding the MAC value through the diode with different temperatures

Additionally, the results of tracking the maximum value are impacted by the period in Repeating Sequence block and the averaging period in Mean Value. Besides, it should be noted that in these figures, there are some ripples of the average current which are unavoidable when using the boost converter.

The instantaneous value of PV array power is shown in Fig. 6 with $\lambda=900 \mathrm{~W} / \mathrm{m}^{2}$, it is obvious that the proposed MAC method could enable tracking the maximum power of PV array by tracking maximum average current through the diode.
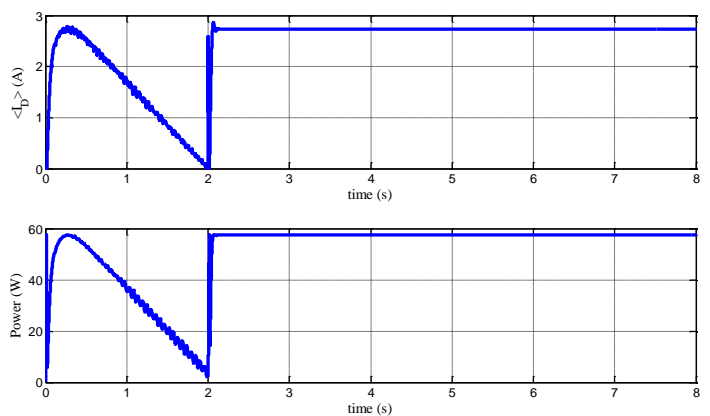

Fig. 6. Tracking and Holding maximum power of PV array by the proposed MAC method.

Table I shows that there is a little difference between the simulation results and the MAC model results. The difference between two models is due to the given period in the Repeating Sequence and the Mean Value. However, this could be reduced by increasing the given period in these blocks. And another impacted factors are 
the small ripples and the losses caused by the elements inside boost converter.

Table I (a). Comparison results between MAC and Simulation modesl with different solar radiations

\begin{tabular}{|c|c|c|c|}
\hline $\begin{array}{c}\text { Solar radiation } \\
\left(\mathbf{k W} / \mathbf{m}^{\mathbf{2}}\right)\end{array}$ & MAC & Simulation & $\begin{array}{c}\text { Error } \\
(\mathbf{\%})\end{array}$ \\
\hline 0.3 & 0.93 & 0.88 & 5.38 \\
\hline 0.6 & 1.91 & 1.82 & 4.71 \\
\hline 0.9 & 2.87 & 2.74 & 4.53 \\
\hline
\end{tabular}

Table I (b). Comparison results between MAC and Simulation models with different temperatures

\begin{tabular}{|c|c|c|c|}
\hline $\begin{array}{c}\text { Temperature } \\
\left({ }^{\mathbf{}} \mathbf{C}\right)\end{array}$ & MAC & Simulation & $\begin{array}{c}\text { Error } \\
(\mathbf{\%})\end{array}$ \\
\hline 15 & 2.87 & 2.74 & 4.53 \\
\hline 35 & 2.42 & 2.28 & 5.79 \\
\hline 55 & 1.95 & 1.84 & 5.64 \\
\hline
\end{tabular}

\section{Conclusion}

The proposed MAC method allows optimizing the electric power which is generated from the PV array close to the maximum power point of the array under changing atmospheric conditions.

In this paper, the difference between the MPPT methods and the proposed MAC method were proven by searching the maximum average current passing through the diode.

Furthermore, the simulation model takes into account the conducting losses in the inductor, diode and switch IGBT. The losses generate the fluctuation during the first few seconds of the holding maximum value period.

\section{Reference}

[1] R.W. Erickson, D. Maksimovic, "Fundametal of Power Electronic", Kluwer Academic Publishers, New York (2000), pp.13-35

[2] T.Markvart, "Solar Electricity", JohnWilly \& Sons, Chichester, England (2000), pp.23-73

[3] O. Wasynezuk, "Dynamic Behavior of a Class of Photovoltaic Power Systems", IEEE Transactions on Power Apparatus and Systems, Sept. 1983, vol.102, no.9, pp.3031-3037

[4] M. Veerachary, T. Senjyu, K. Uezato, "Voltagebased maximum power point tracking control of PV system", IEEE Transactions on Aerospace and Electronic Systems, Jan 2002, vol.38, no.1, pp.262270

[5] Chihchiang Hua, Chihming Shen, "Study of maximum power tracking techniques and control of DC/DC converters for photovoltaic power system," Power Electronics Specialists Conference, 1998. PESC 98 Record. 29th Annual IEEE , 17-22 May 1998, vol.1, pp.86-93

[6] N. Femia, Petrone, G.Spagnuolo, M. Vitelli, "Optimization of perturb and observe maximum power point tracking method," IEEE Transactions on Power Electronics, July 2005, vol.20, no.4, pp. 963- 973

[7] S. Jain, V. Agarwal, "A new algorithm for rapid tracking of approximate maximum power point in photovoltaic systems," Power Electronics Letters, IEEE , March 2004, vol.2, no.1, pp. 16- 19

[8] Yeong-Chau Kuo, Tsorng-Juu Liang, Jiann-Fuh Chen, "Novel maximum-power-point-tracking controller for photovoltaic energy conversion system,", IEEE Transactions on Industrial Electronics, Jun 2001, vol.48, no.3, pp.594-601

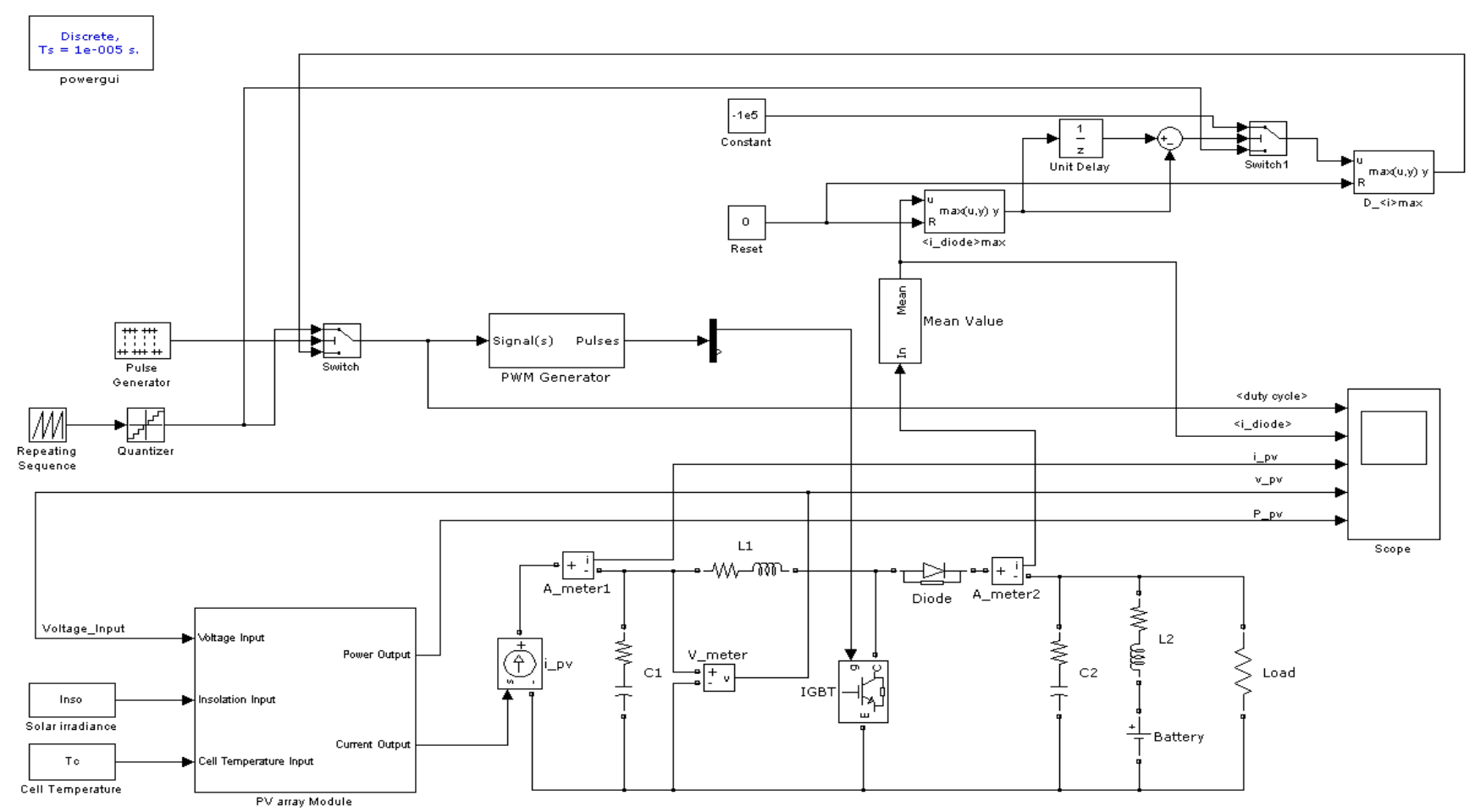

Fig.7. The MAC simulation 